\title{
The mass accommodation coefficient of ozone on an aqueous surface
}

\author{
Birgit Müller and Mathew R. Heal* \\ Department of Chemistry, University of Edinburgh, West Mains Road, Edinburgh, \\ UK EH9 3JJ. E-mail: m.heal@ed.ac.uk
}

Received 11th March 2002, Accepted 3rd May 2002

First published as an Advance Article on the web 11th June 2002

\begin{abstract}
A wetted-wall cylindrical flow reactor was used to measure uptake coefficients, $\gamma$, of $\mathrm{O}_{3}$ on aqueous surfaces at $293 \mathrm{~K}$. The loss of $\mathrm{O}_{3}$ from the gas-phase following contact with varying areas of aqueous surface was determined by UV absorption. The use of $\mathrm{Na}_{2} \mathrm{~S}_{2} \mathrm{O}_{3}$ as an aqueous-phase scavenger for $\mathrm{O}_{3}$ ensured that uptake coefficients were in a reaction-controlled rather than mass accommodation-controlled regime. Observed uptake coefficients were corrected for radial gas-diffusion to yield values of $\gamma^{\text {corr }}$. From extrapolation of a plot of $1 / \gamma^{\text {corr }}$ against the inverse square-root of the $\mathrm{Na}_{2} \mathrm{~S}_{2} \mathrm{O}_{3}$ activity, a value of $\alpha=4 \times 10^{-2}$ was derived for the true mass accommodation coefficient of $\mathrm{O}_{3}$. Evaluation of uncertainties indicate a conservative lower limit of $10^{-2}$ for $\alpha$. The data do not rule out that the upper limit approaches unity. However, it is shown that the measured value of $\alpha$ is sufficiently high that mass accommodation does not limit heterogeneous processing of $\mathrm{O}_{3}$ in the atmosphere for droplets of diameter $>10 \mu \mathrm{m}$. A value of $3.7_{-0.6}^{+0.7} \times 10^{8} \mathrm{~L} \mathrm{~mol}^{-1} \mathrm{~s}^{-1}$ is derived for the aqueous-phase reaction rate coefficient between $\mathrm{O}_{3}$ and $\mathrm{Na}_{2} \mathrm{~S}_{2} \mathrm{O}_{3}$ at $293 \mathrm{~K}$.
\end{abstract}

\section{Introduction}

Recent modelling studies have demonstrated the importance of the condensed aqueous phase (rain, cloud, aerosols, dew drops, etc.) to the chemistry and radical budget of the troposphere. ${ }^{1-4}$ A key parameter in quantifying the transport of a species across the interface from the gas phase is the mass accommodation coefficient, $\alpha$, defined as the probability that an individual molecule striking the liquid surface enters the bulk liquid. Estimates of $\alpha$ are frequently used in models due to the lack of experimental data. ${ }^{4,5}$ Ozone is a key species in the troposphere, acting as an important oxidant in both the gas and aqueous phases. The source of $\mathrm{O}_{3}$ in the aqueous phase is uptake from the gas phase. Although there have been previous experimental measurements of $\alpha$ for $\mathrm{O}_{3}$, there remains considerable variation in the values published in the literature, which was the motivation for the $\alpha$ measurement reported here.

Mass accommodation coefficients are usually derived from experiments which determine the fraction of molecules removed from the gas phase under particular well-controlled conditions. This yields an overall uptake coefficient, $\gamma$, that represents the observed net transport across the interface, incorporating flux due to gas phase diffusion to the surface, the mass accommodation coefficient, diffusion in the liquid phase, and reaction in the liquid phase, if appropriate. The uptake coefficient is usefully approximated by the resistance model formulation, ${ }^{6}$

$$
\frac{1}{\gamma}=\frac{1}{\Gamma_{\mathrm{G}}}+\frac{1}{\alpha}+\frac{1}{\Gamma_{\mathrm{SOL}}+\Gamma_{\mathrm{RXN}}}
$$

in which, by analogy to the terminology of an electric circuit, $1 / \alpha$ is the resistance to mass transfer due to interfacial transfer, and $1 / \Gamma_{\mathrm{G}}, 1 / \Gamma_{\mathrm{SOL}}$ and $1 / \Gamma_{\mathrm{RXN}}$ are the resistances to mass transfer due to gas phase diffusion to the surface, liquid solubility and liquid phase reaction, respectively. The quantities $\Gamma_{\mathrm{G}}, \Gamma_{\mathrm{SOL}}$ and $\Gamma_{\mathrm{RXN}}$ are the corresponding conductances, or dimensionless mass transfer coefficients. Expressions for the liquid solubility and reaction mass transfer coefficients have been derived,: 6

$$
\begin{gathered}
\Gamma_{\mathrm{SOL}}=\frac{4 H R T}{\pi^{1 / 2} \omega} \sqrt{\frac{D_{\mathrm{L}}}{t}} \\
\Gamma_{\mathrm{RXN}}=\frac{4 H R T \sqrt{D_{\mathrm{L}} k_{\mathrm{RXN}}}}{\omega}
\end{gathered}
$$

where $T$ is the temperature, $H$ is the Henry's law coefficient of the trace species, $D_{\mathrm{L}}$ is its diffusion coefficient in the liquid, $R$ is the universal gas constant, $t$ is the liquid-gas contact time, $\omega=\sqrt{8 R T / \pi M}$ (where $M$ is the molar mass) is the mean molecular velocity of the trace species in the gas phase, and $k_{\mathrm{RXN}}$ is the pseudo-first order rate coefficient for a reaction between the transferred species and a reactant in the liquid. The expression for the gas diffusion transfer coefficient, $\Gamma_{\mathrm{G}}$, depends on the specific geometry of the contact surface between gas and liquid phases. In this work, a cylindrical wetted-wall flow reactor was used to measure uptake coefficients for $\mathrm{O}_{3}$ at $293 \mathrm{~K}$. Using the well-established diffusion theory for gas diffusion in cylindrical geometry it is possible to correct experimental uptake coefficients for any limitation to net surface uptake imposed by insufficient rate of radial gas diffusion (see Results section for details). The resulting $\gamma^{\text {corr }}$ values correspond to removal of the $1 / \Gamma_{\mathrm{G}}$ term from the expression for $1 / \gamma$ in eqn. (1).

Ozone neither reacts with pure water nor is particularly soluble in water. The Henry's law coefficient at $293 \mathrm{~K}$ is $1.3 \times 10^{-2} \mathrm{M} \mathrm{atm}^{-1}$. ${ }^{7}$ Therefore uptake of $\mathrm{O}_{3}$ onto pure water surfaces rapidly leads to liquid saturation. However, by adding a suitable scavenger reagent to the aqueous phase to react with $\mathrm{O}_{3}$ it is possible to ensure that $\Gamma_{\mathrm{RXN}} \gg \Gamma_{\mathrm{SOL}}$, i.e. that Henry's law solubility is not reached on the timescale of liquid-gas exposure. Eqn. (1) then simplifies to,

$$
\frac{1}{\gamma^{\text {corr }}}=\frac{1}{\alpha}+\frac{\omega}{4 H R T \sqrt{D_{\mathrm{L}} k_{\mathrm{RXN}}}}
$$

Phys. Chem. Chem. Phys., 2002, 4, 3365-3369 
and the observed (gas diffusion corrected) uptake is a function only of the rate of reaction with the scavenger and not of the contact time between gas and liquid. In this work, $\mathrm{Na}_{2} \mathrm{~S}_{2} \mathrm{O}_{3}$ was added to the water as a reactive scavenger for $\mathrm{O}_{3}$.

\section{Experimental}

The wetted-wall reactor consisted of a vertically mounted tube, through which $\mathrm{O}_{3}$ entrained in He flowed, whose internal walls were covered by a thin aqueous film continuously flowing down under the influence of gravity. The experimental set has been described previously by Müller and Heal. ${ }^{8}$

The glass reactor was about $90 \mathrm{~cm}$ long, with $1.6 \mathrm{~cm}$ internal diameter, and surrounded by a jacket through which coolant could flow. The aqueous solution for the exposed surface was pumped to the reactor by a digital liquid pump (L/S Masterflex with pulse dampener) and filled an annular reservoir at the top of the flow tube. The solution spilled evenly over the lip of the reservoir to form a thin film of flowing liquid, uniformly wetting the entire inner surface of the flow tube. The solution was collected at the bottom of the reactor into a $6 \mathrm{~L}$ flask, which was cooled by an ice-salt mixture to a temperature of about $-15^{\circ} \mathrm{C}$ to prevent back streaming of water vapour into the flow tube. The assumption of uniform wetting of the whole inside wall of the reactor is essential for the data analysis. Experiments were performed only when visual inspection confirmed the wall was completely wetted. Also, since rippling enhances surface absorption rates, ${ }^{9}$ experiments were always conducted in a non-rippling regime (solution flow rates $<150$ $\mathrm{mL} \min ^{-1}$ ).

The main flow of He carrier gas entered the reactor through a side-arm at the top. The gas was humidified before entering the reactor to avoid evaporative cooling of the water film and to maintain a well-defined temperature in the reactor. $\mathrm{O}_{3}$ entered along the centre-line of the reactor through a movable glass injector with an inner diameter of $3 \mathrm{~mm}$. Different exposure times between $\mathrm{O}_{3}$ and liquid surface were achieved by varying the injector position. The $\mathrm{O}_{3}-\mathrm{He}$ mix exited the reactor through a side arm below the wetted film and into a UV absorption cell. All gas flow rates were controlled by calibrated mass flow controllers (Tylan, FC 280 SA). The relative humidity in the reactor was measured using a humidity meter (Vaisala, HMP 234). The temperature of the flowing liquid and the gas were confirmed with thermocouples at the bottom of the reactor. The gas temperature was cross-checked by comparing it with the temperature reading at the humidity meter.

The flow reactor was operated at low pressures, typically a few tens of torr, in order to minimise the magnitude of corrections to observed uptakes arising from radial gas diffusion limitations. Gas pressure was monitored using capacitance manometers (Edwards, Barocel 600AB) at the top of the flow tube and at the UV absorption cell. Linear gas velocities in the reactor (required to convert injector position to gas-surface contact time) were calculated for each experiment taking into account the contribution of water vapour to total gas flow. A typical gas velocity of $\sim 500 \mathrm{~cm} \mathrm{~s}^{-1}$ corresponded to a contact time of $\sim 20 \mathrm{~ms}$ per $10 \mathrm{~cm}$ length exposure to the wetted film. The upper 15-20 $\mathrm{cm}$ of aqueous film was not used for uptake measurements in order to allow thorough mixing and equilibration of water vapour and $\mathrm{He}$.

Changes in $\mathrm{O}_{3}$ gas concentrations following exposure to the aqueous surface were measured by UV absorption at 253.7 $\mathrm{nm}$. Light from a $150 \mathrm{~W}$ Xe lamp (Osram, XBO) was dispersed, after passing through the $90 \mathrm{~cm}$ length absorption cell, by a 300 groove $\mathrm{mm}^{-1}$ grating (in an Instruments SA $270 \mathrm{M}$ Imaging Spectrograph) onto a 1024 element photodiode array (Instrument SA, QuikScan). The integrated software package (Instrument SA, SpectraMax) was used for the control of the spectrograph and for data acquisition. Fig. 1 shows an exam-

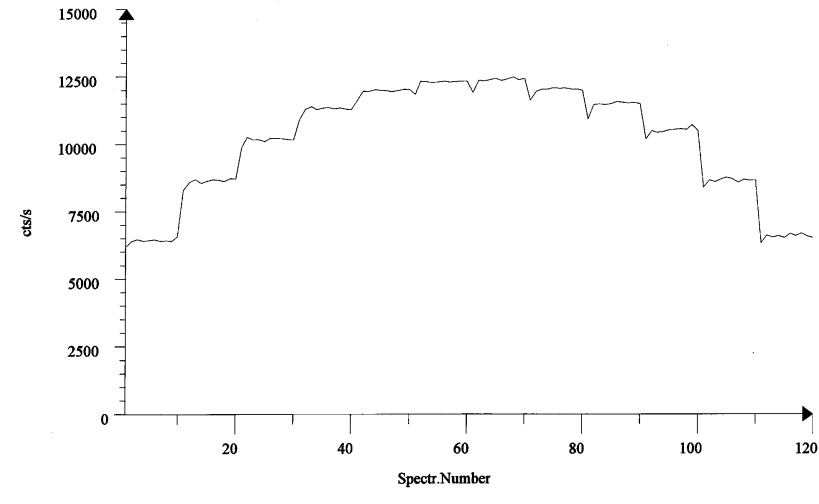

Fig. 1 Example change in absorption signal with change in injector position. 10 spectra were recorded at each of 6 injector positions. The injector was moved out (increasing gas-liquid contact time) for spectra 1 to 60 and moved in for spectra 61 to 120 .

ple of the change in light intensity incident on the photodiode array as the injector is moved in and out of the reactor.

Ozone was produced from a flow of oxygen through an electric-discharge generator (Argentox, GL 10) and absorbed on silica gel in a dry ice-ethanol trap $(\sim 195 \mathrm{~K})$. Mixtures of $\mathrm{O}_{3}$ in $\mathrm{He}$ were prepared on a vacuum line. Solutions of $\mathrm{Na}_{2} \mathrm{~S}_{2} \mathrm{O}_{3}$, (Acros, $>99 \%$ ) used as the scavenger for $\mathrm{O}_{3}$ varied in concentration between 0.02 and $0.20 \mathrm{M}$.

\section{Results}

The loss of $\mathrm{O}_{3}$ from the gas phase by uptake at the internal surface of a cylindrical flow reactor is a first-order process,

$$
\frac{\mathrm{d}\left[\mathrm{O}_{3}\right]}{\mathrm{d} t^{\prime}}=-k_{\mathrm{w}}\left[\mathrm{O}_{3}\right]
$$

where $k_{\mathrm{w}}$ is the first-order rate coefficient and $t^{\prime}$ is the exposure time between gas and liquid surface, which was proportional to injector position up the flow reactor. Since gas phase $\left[\mathrm{O}_{3}\right]$ was directly proportional to absorbance in the absorption cell, values of $k_{\mathrm{w}}$ were determined from the gradients of plots of $\ln$ (absorbance) versus injector position, as shown in Fig. 2. However, if experimental conditions were such that surface uptake was large and/or radial gas diffusion was small, observed $k_{\mathrm{w}}$ underestimated the true first-order rate coefficient because radial diffusion was insufficient to maintain the neces-

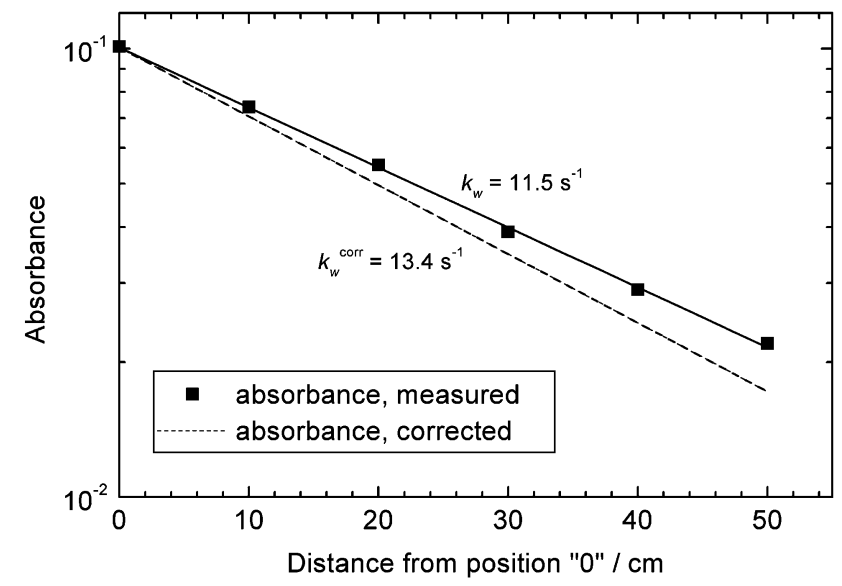

Fig. 2 Log-linear plot of absorbance against injector position before (solid line) and after (dashed line) correction for radial gas-phase $\mathrm{O}_{3}$ concentration gradient, as outlined in the text. Injector position is converted to contact time of gas with liquid surface via the gas velocity (in this experiment, $379 \mathrm{~cm} \mathrm{~s}^{-1}$ ). 
Table 1 Experimental parameters and results for uptake measurements of $\mathrm{O}_{3}$ onto $\mathrm{Na}_{2} \mathrm{~S}_{2} \mathrm{O}_{3}$ solutions at $293 \mathrm{~K}$

\begin{tabular}{|c|c|c|c|c|c|c|}
\hline $\begin{array}{l}\text { Total } \\
\text { pressure } p / \text { Torr }\end{array}$ & $\begin{array}{l}\text { Concentration } \\
{\left[\mathrm{Na}_{2} \mathrm{~S}_{2} \mathrm{O}_{3}\right] / \mathrm{mol} \mathrm{l}^{-1}}\end{array}$ & $\begin{array}{l}\text { Activity } \\
\text { coefficient } \gamma_{\mathrm{Na}_{2} \mathrm{~S}_{2} \mathrm{O}_{3}}\end{array}$ & $\left(c^{\ominus} a_{\mathrm{Na}_{2} \mathrm{~S}_{2} \mathrm{O}_{3}}\right) / \mathrm{mol} \mathrm{l}^{-1}$ & $k_{\mathrm{w}} / \mathrm{s}^{-1}$ & $k_{\mathrm{w}}^{\mathrm{corr}} / \mathrm{s}^{-1}$ & $\begin{array}{l}\text { Corrected uptake } \\
\text { coefficient } \gamma^{\text {corr }}\end{array}$ \\
\hline 12.0 & 0.1990 & 0.393 & 0.07820 & 17.6 & 21.8 & $9.73 \times 10^{-4}$ \\
\hline 17.1 & 0.0991 & 0.464 & 0.04595 & 12.8 & 15.3 & $6.84 \times 10^{-4}$ \\
\hline 19.0 & 0.0763 & 0.485 & 0.03699 & 10.2 & 11.8 & $5.54 \times 10^{-4}$ \\
\hline 15.0 & 0.0598 & 0.504 & 0.03016 & 11.5 & 13.4 & $5.98 \times 10^{-4}$ \\
\hline 17.1 & 0.0410 & 0.539 & 0.02209 & 8.9 & 10.0 & $4.48 \times 10^{-4}$ \\
\hline 19.6 & 0.0359 & 0.553 & 0.01984 & 8.8 & 10.0 & $4.48 \times 10^{-4}$ \\
\hline 18.0 & 0.0309 & 0.571 & 0.01763 & 8.5 & 9.5 & $4.25 \times 10^{-4}$ \\
\hline 18.0 & 0.0309 & 0.571 & 0.01763 & 8.4 & 9.5 & $4.22 \times 10^{-4}$ \\
\hline 14.0 & 0.0203 & 0.627 & 0.01270 & 7.5 & 8.2 & $3.75 \times 10^{-4}$ \\
\hline
\end{tabular}

sary flux of $\mathrm{O}_{3}$ molecules to the surface. This corresponds to a significant gas-phase diffusion resistance term, $1 / \Gamma_{\mathrm{G}}$, in eqn. (1). The observed values of $k_{\mathrm{w}}$ were therefore corrected for the effect of a radial concentration gradient to yield $k_{\mathrm{w}}^{\text {corr }}$, using a computer program following the algorithm of Brown. ${ }^{10} \mathrm{An}$ example correction is shown in Fig. 2. Finally, the gas-corrected uptake coefficient, $\gamma^{\text {corr }}$, corresponding to the first-order loss coefficient in cylindrical geometry was calculated from,

$$
\gamma^{\mathrm{corr}}=\frac{2 r k_{\mathrm{w}}^{\mathrm{corr}}}{\omega}
$$

where $r$ was the radius of the reactor. ${ }^{11}$ The pressure-independent binary gas diffusion coefficients of $\mathrm{O}_{3}$ in water vapour and He required for the correction method of Brown were calculated to be 175 Torr $\mathrm{cm}^{2} \mathrm{~s}^{-1}$ and 507 Torr $\mathrm{cm}^{2} \mathrm{~s}^{-1}$, respectively, using the Fuller-Schettler-Giddings estimation method. ${ }^{12}$

Assuming that the reaction between $\mathrm{O}_{3}$ and $\mathrm{Na}_{2} \mathrm{~S}_{2} \mathrm{O}_{3}$ is second-order with rate coefficient, $k^{\prime \prime}$, and that $\mathrm{Na}_{2} \mathrm{~S}_{2} \mathrm{O}_{3}$ is in excess, yields, from eqn. (4),

$$
\frac{1}{\gamma^{\text {corr }}}=\frac{1}{\alpha}+\frac{\omega}{4 H R T \sqrt{D_{\mathrm{L}} k^{\prime \prime} c^{\ominus} a_{\mathrm{Na}_{2} \mathrm{~S}_{2} \mathrm{O}_{3}}}}
$$

where $a_{\mathrm{Na}_{2} \mathrm{~S}_{2} \mathrm{O}_{3}}$ is the dimensionless activity of $\mathrm{Na}_{2} \mathrm{~S}_{2} \mathrm{O}_{3}$ and $c^{-}$ is the standard concentration of $1.0 \mathrm{~mol} \mathrm{~L}^{-1}$. The activity and concentration of $\mathrm{Na}_{2} \mathrm{~S}_{2} \mathrm{O}_{3}$ are related through,

$$
a_{\mathrm{Na}_{2} \mathrm{~S}_{2} \mathrm{O}_{3}}=\frac{\gamma_{\mathrm{Na}_{2} \mathrm{~S}_{2} \mathrm{O}_{3}}}{c^{\ominus}}\left[\mathrm{Na}_{2} \mathrm{~S}_{2} \mathrm{O}_{3}\right]
$$

where $\gamma_{\mathrm{Na}_{2} \mathrm{~S}_{2} \mathrm{O}_{3}}$ is the activity coefficient. Values of $\gamma_{\mathrm{Na}_{2} \mathrm{~S}_{2} \mathrm{O}_{3}}$ were obtained from Robinson and Stokes. ${ }^{13}$ Measurements of uptake were repeated for different concentrations of $\mathrm{Na}_{2} \mathrm{~S}_{2} \mathrm{O}_{3}$ and the relevant experimental data and results are given in Table 1.

Eqn. (7) indicates that a plot of $\log \left(\gamma^{\text {corr }}\right)$ against $\log \left(c^{\ominus} a_{\mathrm{Na}_{2} \mathrm{~S}_{2} \mathrm{O}_{3}}\right)$ should be a straight line with gradient 0.5 if uptake experiments were conducted in a reaction-controlled rather than mass accommodation-controlled regime, i.e. for $\omega /\left(4 H R T \sqrt{D_{\mathrm{L}} k^{\prime \prime} c^{\ominus} a_{\mathrm{Na}_{2} \mathrm{~S}_{2} \mathrm{O}_{3}}}\right) \gg 1 / \alpha$. Fig. 3 shows this plot for the experiments presented here. The linearity of the data (correlation coefficient, $r=0.98$ ) and the gradient of $0.52 \pm 0.05$ confirm that the measured uptake coefficient of $\mathrm{O}_{3}$ was not limited by mass accommodation, i.e. that $\alpha$ must significantly exceed the observed uptake coefficient even for the highest concentrations of $\mathrm{Na}_{2} \mathrm{~S}_{2} \mathrm{O}_{3}$ scavenger used. From Table 1 it is therefore possible to conclude that $\alpha$ must certainly exceed $10^{-3}$.

Eqn. (7) also indicates that a plot of $1 / \gamma^{\text {corr }}$ against $1 / \sqrt{c^{\ominus} a_{\mathrm{Na}_{2} \mathrm{~S}_{2} \mathrm{O}_{3}}}$ should be a straight line of gradient $\omega /\left(4 H R T \sqrt{D_{\mathrm{L}} k^{\prime \prime}}\right)$ and intercept $1 / \alpha$, and this is shown in Fig. 4. The intercept of 24 yields a value of $\alpha=4 \times 10^{-2}$. The statistical error in the intercept from the regression yields a lower limit of $\alpha \sim 3 \times 10^{-3}$ (at 95\% confidence). However, for

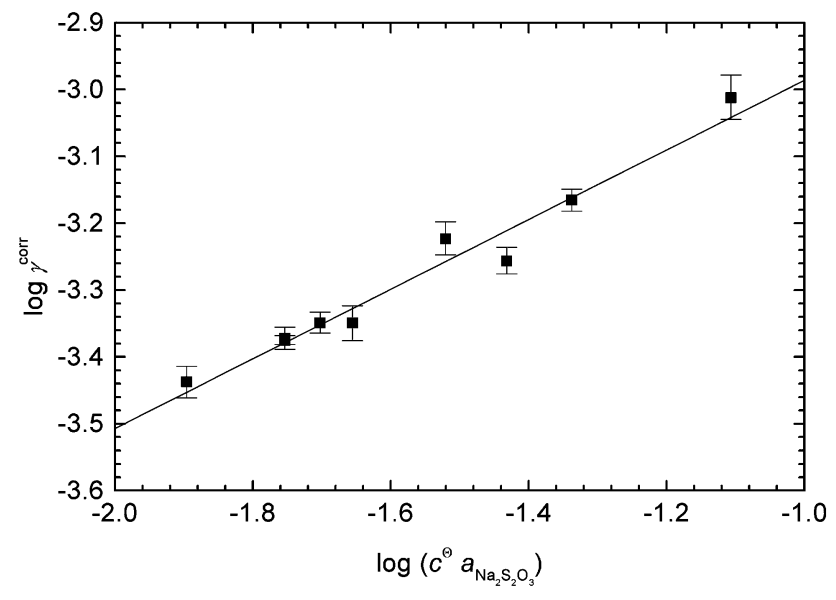

Fig. 3 Plot of $\log \left(\gamma^{\text {corr }}\right)$ against $\log \left(c^{-} a_{\mathrm{Na}_{2} \mathrm{~S}_{2} \mathrm{O}_{3}}\right)$ for the gas-diffusion corrected reactive uptake of $\mathrm{O}_{3}$ on $\mathrm{Na}_{2} \mathrm{~S}_{2} \mathrm{O}_{3}$ solution at $293 \mathrm{~K}$. The error bars of the individual points are the statistical errors only in the fits of the plots to derived values of $k_{\mathrm{w}}$. The solid line is the least-squares linear fit to the data $(r=0.98)$ and has a gradient of $0.52 \pm 0.05$ (standard error of slope)

resistance due to mass accommodation to be small in comparison with resistance due to liquid reaction (values of $\gtrsim 1000$ for the latter are obtained by substituting data appropriate to the experimental conditions into the expression for $\left.1 / \Gamma_{\mathrm{RXN}}\right)$,

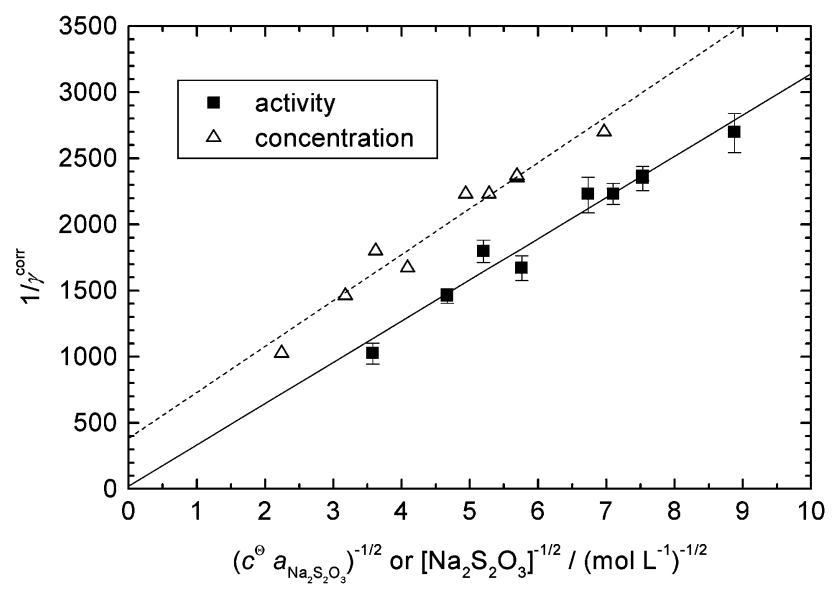

Fig. 4 Plot of $1 / \gamma^{\text {corr }}$ against $1 / \sqrt{c^{\ominus} a_{\mathrm{Na}_{2} \mathrm{~S}_{2} \mathrm{O}_{3}}}$ (squares) and against $1 / \sqrt{\left[\mathrm{Na}_{2} \mathrm{~S}_{2} \mathrm{O}_{3}\right]}$ (triangles). The solid and dashed lines are linear fits to the activity and concentration data, respectively. The slope and intercept of the former have values $310 \mathrm{~mol}^{1 / 2} \mathrm{~L}^{-1 / 2}$ and 24 , and correspond to $\omega /\left(4 H R T \sqrt{D_{\mathrm{L}} k^{\prime \prime}}\right)$ and $1 / \alpha$, respectively. The error bars of the individual points are the statistical errors only in the fits of the plots to derived values of $k_{\mathrm{w}}$. 
requires a more appropriate lower limit to $\alpha$ of $\sim 10^{-2}$. The upper uncertainty limit to $\alpha$ derived from Fig. 4 corresponds to a negative intercept, which is not physically possible. The statistical uncertainties are large because the extrapolation of the data to the intercept is extremely sensitive to the linear fit. Overall, however, the best estimate from these data is that $\alpha \sim 4 \times 10^{-2}$ but that the error range encompasses values from $10^{-2}$ towards unity.

The gradient of $310 \mathrm{~mol}^{1 / 2} \mathrm{~L}^{-1 / 2}$ in Fig. 4 yields a value of $k^{\prime \prime}=\left(3.7_{-0.6}^{+0.7}\right) \times 10^{8} \mathrm{~L} \mathrm{~mol}^{-1} \mathrm{~s}^{-1}$ for the aqueous-phase reaction between $\mathrm{O}_{3}$ and $\mathrm{Na}_{2} \mathrm{~S}_{2} \mathrm{O}_{3}$ at $293 \mathrm{~K}$. The method of Wilke and Chang, as described in Reid et al., ${ }^{12}$ was used to calculate the liquid diffusion coefficient of $D_{\mathrm{L}}=2.30 \times 10^{-5} \mathrm{~cm}^{2} \mathrm{~s}^{-1}$ for $\mathrm{O}_{3}$ in water at $293 \mathrm{~K}$ required to derive $k^{\prime \prime}$. A Henry's law coefficient of $H=1.3 \times 10^{-2} \mathrm{M} \mathrm{atm}^{-1}$ at $293 \mathrm{~K}$ was derived from Kosak-Channing and Helz. ${ }^{7}$ The quoted uncertainties are the statistical errors in the linear regression in Fig. 4.

\section{Discussion}

\section{Possible sources of measurement error in $\gamma$ and $\alpha$}

The major potential source of error is variation in the relative humidity of the gas flow which is required to calculate the gas velocity and the overall gas diffusion coefficient. These parameters impact on the derivation of $k_{\mathrm{w}}$ and $k_{\mathrm{w}}^{\mathrm{corr}}$, and ultimately of $\gamma^{\text {corr }}$ and $\alpha$. Relative humidity is a strong function of temperature, hence the need for accurate and precise control of the experimental conditions in the flow tube. A realistic estimate of the overall error in $\gamma^{\text {corr }}$ due to uncertainties in the relative humidity and minor fluctuations in temperature and pressure along the flow tube is $\pm 20 \%$. Propagating these uncertainties does not affect the overall estimate for $\alpha>10^{-2}$ discussed above.

\section{Salt activity}

Some researchers neglect to use activity in the data treatment for reactive uptake and use concentrations instead. For example, Fickert et al. ${ }^{14}$ used $\left[\mathrm{Br}^{-}\right]$up to $0.1 \mathrm{M}$ when investigating uptake of $\mathrm{ClNO}_{2}$. The effect on the data analysis of using concentrations rather than activities for the work presented here is shown as the dashed line in Fig. 4. The intercept of this plot yields $\alpha=2.6 \times 10^{-3}$. The difference in $\alpha$ between the two approaches is significant (about a factor of 16). The implied resistance of 385 due to mass accommodation $(1 / \alpha)$ obtained from the concentration plot is not credible given that it has already been shown that uptake in these experiments was in the reaction-controlled regime. This shows it is important that activities rather than concentrations are used in all analyses.

The possible effect of ionic strength on the liquid diffusion coefficient must also be considered. Akita ${ }^{15}$ has presented a method to predict diffusivities of gases in aqueous electrolyte solutions, if gas diffusivities in pure water and the densities of the solutions are available. Application of the method to the experimental conditions here decreased the liquid diffusion coefficient of $\mathrm{O}_{3}$ in $\mathrm{Na}_{2} \mathrm{~S}_{2} \mathrm{O}_{3}$ by about $5 \%$ to $D_{\mathrm{L}}=2.18 \times 10^{-5}$ $\mathrm{cm}^{2} \mathrm{~s}^{-1}$. Although the modification is systematic, it is within the general uncertainty range of the Wilke and Chang estimation method ${ }^{12}$ and can therefore be ignored.

\section{Effect of ionic strength on Henry's law coefficient}

The effect on the Henry's law coefficient for $\mathrm{O}_{3}$ from the presence of $\mathrm{Na}_{2} \mathrm{~S}_{2} \mathrm{O}_{3}$ in the solution should also be considered. The scavenger concentrations used in this study ranged from 0.02 to $0.2 \mathrm{~mol} \mathrm{~L}^{-1}$ which correspond to ionic strengths of 0.06 to $0.6 \mathrm{~mol} \mathrm{~L}^{-1}$. Although data are not available specifically for $\mathrm{Na}_{2} \mathrm{~S}_{2} \mathrm{O}_{3}$, Kosak-Channing and $\mathrm{Helz}^{7}$ reported the
Table 2 Estimated Henry's law coefficient of $\mathrm{O}_{3}$ in $\mathrm{Na}_{2} \mathrm{~S}_{2} \mathrm{O}_{3}$ at $293 \mathrm{~K}$ as a function of ionic strength. $k_{\mathrm{S}}^{\prime \prime}$ is the rate coefficient of ozone with $\mathrm{Na}_{2} \mathrm{~S}_{2} \mathrm{O}_{3}$ in electrolyte

\begin{tabular}{llll}
\hline$\left[\mathrm{Na}_{2} \mathrm{~S}_{2} \mathrm{O}_{3}\right] / \mathrm{mol} \mathrm{L}^{-1}$ & $I_{\mathrm{S}} / \mathrm{mol} \mathrm{L}^{-1}$ & $H_{\mathrm{S}} \mathrm{O}_{3} / \mathrm{M} \mathrm{atm}^{-1}$ & $k_{\mathrm{S}}^{\prime \prime} / \mathrm{L} \mathrm{mol}^{-1} \mathrm{~s}^{-1}$ \\
\hline 0.1990 & 0.597 & $1.081 \times 10^{-2}$ & $5.3 \times 10^{8}$ \\
0.0991 & 0.297 & $1.186 \times 10^{-2}$ & $4.4 \times 10^{8}$ \\
0.0763 & 0.229 & $1.211 \times 10^{-2}$ & $4.2 \times 10^{8}$ \\
0.0598 & 0.180 & $1.230 \times 10^{-2}$ & $4.1 \times 10^{8}$ \\
0.0410 & 0.123 & $1.252 \times 10^{-2}$ & $4.0 \times 10^{8}$ \\
0.0359 & 0.108 & $1.258 \times 10^{-2}$ & $3.9 \times 10^{8}$ \\
0.0309 & 0.093 & $1.263 \times 10^{-2}$ & $3.9 \times 10^{8}$ \\
0.0203 & 0.061 & $1.276 \times 10^{-2}$ & $3.8 \times 10^{8}$ \\
\hline
\end{tabular}

change in Henry's law coefficient of $\mathrm{O}_{3}$ with ionic strength using solutions of $\mathrm{Na}_{2} \mathrm{SO}_{4}$.

The Henry's law coefficient of ozone in ionic solution, $H_{\mathrm{S}}{ }^{\mathrm{O}_{3}}$, for the salt concentrations used here were calculated from the Setchenow expression, using data for $\mathrm{Na}_{2} \mathrm{SO}_{4}$ as a surrogate for $\mathrm{Na}_{2} \mathrm{~S}_{2} \mathrm{O}_{3}$, i.e.

$$
\log \frac{H^{\mathrm{O}_{3}}}{H_{\mathrm{S}} \mathrm{O}_{3}}=k_{\mathrm{S}}\left[\mathrm{Na}_{2} \mathrm{SO}_{4}\right]
$$

where $H^{\mathrm{O}_{3}}$ and $H_{\mathrm{S}} \mathrm{O}_{3}$ are the Henry's law coefficient of ozone in pure water and in the salt solution, respectively, $\left[\mathrm{Na}_{2} \mathrm{SO}_{4}\right]$ is the molarity of the $\mathrm{Na}_{2} \mathrm{SO}_{4}$ solution and $k_{\mathrm{S}}$ is the Setchenow salting-out coefficient $\left(\mathrm{L} \mathrm{mol}{ }^{-1}\right)$. The quantity $k_{\mathrm{S}}$ can be described as the sum of contributions of the negative and positive species in solution and of the gas ${ }^{9}$

$$
k_{\mathrm{S}}=k_{\mathrm{S}} \mathrm{Na}^{+}+k_{\mathrm{S}} \mathrm{SO}_{4}^{2-}+k_{\mathrm{S}} \mathrm{O}_{3} \text {. }
$$

Values for $k_{\mathrm{S}} \mathrm{Na}^{+}$and $k_{\mathrm{S}}{ }^{\mathrm{SO}_{4}{ }^{2-}}$ were taken from Danckwerts ${ }^{9}$ and are independent of temperature. Magi et al. ${ }^{16}$ provide a value of $k_{\mathrm{S}} \mathrm{O}_{3}$ at $293 \mathrm{~K}$, based on the results of Kosak-Channing and $\mathrm{Helz}^{7}$ for $\mathrm{Na}_{2} \mathrm{SO}_{4}$ solutions. This leads to a value of $k_{\mathrm{S}}=0.134 \mathrm{~L} \mathrm{~mol}^{-1}$. Values of $H_{\mathrm{S}}{ }^{\mathrm{O}_{3}}$ calculated for the different experimental salt concentrations of $\mathrm{Na}_{2} \mathrm{~S}_{2} \mathrm{O}_{3}$ used in this study are given in Table 2. Both approaches to calculating $H_{\mathrm{S}} \mathrm{O}_{3}$, namely, calculation via salting-out coefficients of single ions and the experimental values determined for four ionic strength by Kosak-Channing and Helz ${ }^{7}$ agree.

Since the slope of the solid line in Fig. 4 is linear, the product $H_{\mathrm{S}}{ }^{\mathrm{O}_{3}} \sqrt{k_{\mathrm{S}}^{\prime \prime}}$ is constant and the second-order rate constant $k_{\mathrm{S}}^{\prime \prime}$ in the electrolyte can be calculated which takes into account the ionic strength. These calculated values for $k_{\mathrm{S}}^{\prime \prime}$ are listed in Table 2 and they increase with ionic strength. However, all values of $k_{\mathrm{S}}^{\prime \prime}$ are within the error limit of $k^{\prime \prime}$, apart from at the highest ionic strength. Therefore, the effect of ionic strength on Henry's law coefficient was neglected.

\section{Comparison with previous measurements}

The combined interpretation of the data from Table 1 and Figs. 3 and 4 place a likely lower limit of $10^{-2}$ on $\alpha$ for $\mathrm{O}_{3}$ on water at $293 \mathrm{~K}$. A better estimate is $4 \times 10^{-2}$, but the value may be closer to unity.

Published values of $\alpha$ and $k^{\prime \prime}$ are compared in Table 3. The value of $\alpha=\sim 4 \times 10^{-2}$ (lower limit $>10^{-2}$ ) obtained in this work is consistent with the measurements by Utter et al. ${ }^{17}$ $\mathrm{Hu}$ et al. ${ }^{18}$ and Magi et al. ${ }^{16}$ The latter two studies estimate values of $10^{-1}$ or greater. It is now clear that the early measurements of $\alpha$ by Tang and Lee ${ }^{19}$ and by Wunderlich, as cited in Magi et al., ${ }^{16}$ are far too low. In fact, the value from this work agrees very well with the value of $\alpha>2 \times 10^{-2}$ published by Schütze and Herrmann ${ }^{20}$ just as this manuscript was being prepared, and both measurements support the value of $\alpha=5 \times 10^{-2}$ currently specified for $\mathrm{O}_{3}$ in the detailed 
Table 3 Comparison of values of $\mathrm{O}_{3}$ mass accommodation coefficient and liquid scavenger rate coefficients

\begin{tabular}{|c|c|c|c|c|c|}
\hline$\alpha$ & $T / \mathrm{K}$ & Comment & $\begin{array}{l}\text { Liquid scavenger } \\
\text { species }\end{array}$ & $\begin{array}{l}k^{\prime \prime} \text { for reaction of } \mathrm{O}_{3} \text { with } \\
\text { scavenger } / \mathrm{L} \mathrm{mol}^{-1} \mathrm{~s}^{-1}\end{array}$ & Reference \\
\hline $2 \times 10^{-3}$ to 1 & 276 & & $\begin{array}{l}\mathrm{SO}_{3}{ }^{2-} \\
\mathrm{S}_{2} \mathrm{O}_{3}{ }^{2-} \\
\mathrm{Sn}^{2+}\end{array}$ & $\begin{array}{l}3.9 \times 10^{8} \\
2.2 \times 10^{8} \\
8.5 \times 10^{8}\end{array}$ & Utter et al. ${ }^{17}$ \\
\hline 0.1 & 277 & Considered an estimate & $\mathrm{I}^{-}$ & $4 \times 10^{9}$ & Hu et al. ${ }^{18}$ \\
\hline 0.1 & 281 & As lower limit & $\mathrm{I}^{-}$ & $\begin{array}{l}3.2 \times 10^{8}(\text { at } 275 \mathrm{~K}) \\
\quad \text { to } 2.4 \times 10^{9}(\text { at } 293 \mathrm{~K})\end{array}$ & Magi et al. ${ }^{16}$ \\
\hline $5.3 \times 10^{-4}$ & 283 & & $\mathrm{SO}_{3}{ }^{2-}$ & & Tang and Lee ${ }^{19}$ \\
\hline $5 \times 10^{-3}$ & RT & $\begin{array}{l}\text { Possibly underestimated } \\
\left(\text { low } k^{\prime \prime}\right)\end{array}$ & $\mathrm{I}^{-}$ & $1 \times 10^{6}$ & $\begin{array}{l}\text { Wunderlich as cited } \\
\text { in Magi et al. }{ }^{16}\end{array}$ \\
\hline $4 \times 10^{-2}$ & 293 & & $\mathrm{~S}_{2} \mathrm{O}_{3}{ }^{2-}$ & $3.7 \times 10^{8}$ & This work \\
\hline$>2 \times 10^{-2}$ & 298 & & $\mathrm{I}^{-}$ & $9.6 \times 10^{9}\left(\mathrm{~L}^{2} \mathrm{~mol}^{-2} \mathrm{~s}^{-1}\right)$ & Schütze and Herrmann ${ }^{20}$ \\
\hline
\end{tabular}

CAPRAM mechanism for tropospheric multiphase chemistry. ${ }^{4}$

The only previous measurement of $k^{\prime \prime}$ for the aqueous-phase reaction between $\mathrm{O}_{3}$ and $\mathrm{Na}_{2} \mathrm{~S}_{2} \mathrm{O}_{3}$ is a value of $2.2 \times 10^{8} \mathrm{~L}$ $\mathrm{mol}^{-1} \mathrm{~s}^{-1}$ at $276 \mathrm{~K}^{17}$ Combining this with the value $3.7 \times 10^{8} \mathrm{~L} \mathrm{~mol}^{-1} \mathrm{~s}^{-1}$ obtained here at $293 \mathrm{~K}$, and assuming that the temperature dependence of the reaction is described by the Arrhenius equation yields an activation energy for the reaction of $\sim 20 \mathrm{~kJ} \mathrm{~mol}^{-1}$. The calculation is of very limited confidence, of course, since measurements at only two temperatures are available.

\section{Conclusion}

Although some uncertainty still remains as to the precise value of $\alpha$ for $\mathrm{O}_{3}$ it is now clear that it must exceed a few percent. The value of $\Gamma_{\mathrm{G}}$ for gas-phase diffusion to the surface of a spherical droplet is ${ }^{6}$

$$
\Gamma_{\mathrm{G}}=\left(\frac{\omega d}{8 D_{\mathrm{G}}}-\frac{1}{2}\right)^{-1}
$$

where $d$ is the diameter of the droplet and $D_{\mathrm{G}}$ is the diffusion coefficient of the species in air. Therefore, mass accommodation limits the rate of mass transfer across the interface when $\alpha<\Gamma_{\mathrm{G}}$, or when droplet diameter,

$$
d<\frac{8 D_{\mathrm{G}}}{\omega}\left(\frac{1}{\alpha}+\frac{1}{2}\right)
$$

Substituting $\alpha \sim 0.04, \omega \sim 3.6 \times 10^{4} \mathrm{~cm} \mathrm{~s}^{-1}$ and $D_{\mathrm{G}} \sim 0.2 \mathrm{~cm}^{2}$ $\mathrm{s}^{-1}$ for $\mathrm{O}_{3}$ in air at $1 \mathrm{~atm}$ into eqn. (12) shows that the interfacial transfer of $\mathrm{O}_{3}$ under atmospheric conditions is limited by mass accommodation only for droplets of diameter $<10 \mu \mathrm{m}$. Since the majority of tropospheric water content resides in droplets of diameters $>10 \mu \mathrm{m}$ it can be concluded that the rate of heterogeneous processing of $\mathrm{O}_{3}$ is controlled by whichever is the slower of gas-phase diffusion to the surface or liquid-phase reaction. However, models that specifically intend to consider $\mathrm{O}_{3}$ heterogeneous processes on the fraction of the aqueous aerosol distribution with $d<10 \mu \mathrm{m}$ must explicitly take mass accommodation into account.

\section{References}

1 J. Lelieveld and P. J. Crutzen, Nature, 1990, 343, 227.

2 W. L. Chameides and A. W. Stelson, J. Geophys. Res., [Atmos.], 1992, 97, 20565.

3 M. Leriche, D. Voisin, N. Chaumerliac, A. Monod and B. Aumont, Atmos. Environ., 2000, 34, 5015.

4 H. Herrmann, B. Ervens, H. W. Jacobi, R. Wolke, P. Nowacki and R. Zellner, J. Atmos. Chem., 2000, 36, 231.

5 W. L. Chameides, J. Geophys. Res., 1984, 89, 4739.

6 C. E. Kolb, D. R. Worsnop, M. S. Zahniser, P. Davidovits, L. F. Keyser, M. T. Leu, M. J. Molina, D. R. Hanson, A. R. Ravishankara, L. R. Williams, M. A. Tolbert, Laboratory Studies of Atmospheric Heterogeneous Chemistry, in Progress and Problems in Atmospheric Chemistry, ed. J. R. Barker, World Scientific, Singapore, 1995, pp. 771-875.

7 L. F. Kosak-Channing and G. R. Helz, Environ. Sci. Technol., 1983, 17, 145.

8 B. Müller and M. R. Heal, J. Phys. Chem. A, 2002, 106, 5120.

9 P. V. Danckwerts, Gas-liquid reactions, McGraw-Hill, New York, 1970.

10 R. L. Brown, J. Res. Natl. Bur. Stand. (US), 1978, 83, 1.

11 C. J. Howard, J. Phys. Chem., 1979, 83, 3.

12 R. C. Reid, J. M. Prausnitz, B. E. Poling, The properties of gases and liquids, McGraw Hill, New York, 1987.

13 R. A. Robinson, R. H. Stokes, Electrolyte solutions: the measurement and interpretation of conductance, chemical potential and diffusion in solutions of simple electrolytes, Butterworths, London, 1959.

14 S. Fickert, F. Helleis, J. W. Adams, G. K. Moortgat and J. N. Crowley, J. Phys. Chem. A, 1998, 102, 10689.

15 K. Akita, Ind. Eng. Chem. Fundam., 1981, 20, 89.

16 L. Magi, F. Schweitzer, C. Pallares, S. Cherif, P. Mirabel and C. George, J. Phys. Chem. A, 1997, 101, 4943.

17 R. G. Utter, J. B. Burkholder, C. J. Howard and A. R. Ravishankara, J. Phys. Chem., 1992, 96, 4973.

18 J. H. Hu, Q. Shi, P. Davidovits, D. R. Worsnop, M. S. Zahniser and C. E. Kolb, J. Phys. Chem., 1995, 99, 8768.

19 I. N. Tang and J. H. Lee, ACS Symp. Ser., 1987, 349, 109.

20 M. Schütze and H. Herrmann, Phys. Chem. Chem. Phys., 2002, 4, 60 . 